\title{
Claves para el estudio del cine documental del ICAIC en los años ochenta: crítica social, humor y sinergia entre ficción y no-ficción
}

\author{
Keys for the study of Documentary Cinema of ICAIC in the 80s: Social Criticism, \\ Humour and Sinergy between Fiction and Non-Fiction
}

Maria del Carmen Tamayo Asef ${ }^{*}$ y Carlos Guillermo Lloga Sanz ${ }^{* *}$

\begin{abstract}
Resumen: El artículo analiza el documental cubano producido por el Instituto Cubano de Arte e Industria Cinematográficos (ICAIC) en los años ochenta. Propone una reinterpretación del mismo en oposición al criterio expandido que cataloga la producción de documental de estos años como complaciente y populista. Este texto defiende una postura diferente al considerar los filmes como productos culturales de una época convulsa que desarrollaron elementos estéticos poco vistos anteriormente en la documentalística cubana. El presente estudio examina la crítica social, el humor y la sinergia entre ficción y no-ficción como variables que contribuyen a evaluar los recursos cinematográficos desplegados por el documental en esta etapa. Finalmente, se exploran poéticas individuales de los realizadores destacados y los filmes más sobresalientes del período.
\end{abstract}

Palabras clave: Documental, cine cubano, ICAIC, crítica social, humor, performatividad

\begin{abstract}
The article analizes Cuban documentary film produced by Instituto Cubano de Arte e Industria Cinematográficos (ICAIC) during the 80s. It proposes a reinterpretation in opposition to the expanded opinion that catalogues documentary production of these years as indulgent and populist. This text defends a different posture by considering films as cultural products of a convulse time which developed aesthetical elements non-seen previously in Cuban documentary film. The present study examines social criticism, humour, and synergy between fiction and non-fiction as variables which contribute to assess the cinematic resources used by documentary on this period. Finally, individual poetics of prominent filmmakers and outstanding films are explored.
\end{abstract}

\footnotetext{
${ }^{*}$ Cubana, coautora. Lic. en Historia del Arte (Universidad de Oriente). Especialista del Centro Provincial de Artes Plásticas y Diseño de Santiago de Cuba. E-mail: mariaasef94@gmail.com

${ }^{* *}$ Cubano, coautor, Dr. en Film Studies and Visual Culture (University of Antwerp). Profesor Asistente de la Universidad de Oriente en Santiago de Cuba, Departamento de Historia del Arte. E-mail: carloslloga@uo.edu.cu
} 
Keywords: Documentary, Cuban Cinema, ICAIC, social criticism, humour, performativity

Recibido: 18 junio 2019 Aceptado: 10 septiembre 2019

\section{Preludio de los ochenta: el género documental dentro de la cultura cinematográfica cubana}

El documental ha alcanzado un desarrollo importante en Cuba. El trabajo del Instituto Cubano de Arte e Industria Cinematográficos (ICAIC) desde su fundación en 1959 fue cardinal en la proliferación de esta forma audiovisual y en su concepción como fenómeno artístico. La urgencia por registrar los eventos en un ambiente político convulso y el apoyo institucional para la realización, fueron factores que asistieron al realce del género. ${ }^{1}$ En aquellos momentos, las condiciones para el desarrollo del cine de no ficción en Cuba eran excepcionales, pues era "el único lugar en Latinoamérica donde los documentales locales eran ampliamente vistos en los cines." 2

En los estudios de cine cubano, el género documental cuenta con una historia particular. La mayoría de la literatura se enfoca en analizar y tipificar elementos de la producción del ICAIC. ${ }^{3}$ Dentro de la misma, atención particular han recibido los filmes realizados en los años sesenta, conocida como la "época de oro" del documental en Cuba, ${ }^{4}$ debido a los notables resultados estéticos alcanzados y su reconocimiento internacional en festivales y eventos relevantes. ${ }^{5}$

El documental estableció un modelo representacional que fue internacionalizado y que, en gran medida, construyó el discurso visual de la primera década de la Revolución. ${ }^{6}$ Varios especialistas han señalado la maduración temprana de un estilo alrededor del género, ${ }^{7}$ el cual,

1 Jorge Luis Sánchez, Romper la tensión del arco. Movimiento cubano de cine documental, La Habana, Ediciones ICAIC, 2010.

2 Michael Chanan, Cuban Cinema, Minnesota, University of Minneapolis Press, 2004, p. 4.

3 Juan Antonio García Borrero, El perfecto neoanalfabeto y otras bloguerías, Santiago de Cuba, Editorial Oriente.

4 El término es común en los estudios sobre cine en Cuba. Véase: Luciano Castillo, "Rápida mirada al cine de los soñadores", Luciano Castillo, et al, Conquistando la utopía. El ICAIC y la Revolución 50 años después, La Habana, ICAIC, 2010, pp. 11-41; Joel del Río y Enrique Colina, “Memories of Cuban Cinema, 1959-2015”, Maria Delgado, Stephen Hart y Randall Johnson (eds.), A Companion to Latin American Cinema, Oxford, Wiley-Blackwell, 2007, pp. 219-237; Mario Naito, "El documental cubano desde sus orígenes hasta nuestros días", Mario Naito (ed.), Coordenadas de cine cubano 2, Santiago de Cuba, Editorial Oriente, pp. 105-121; Carlos G. Lloga y David Silveira, "Perspectivas de consenso y conflicto en el documental cubano de los sesenta. La hermenéutica ontológica como estrategia de interpretación de la realidad", Santiago $N^{\circ} 145,2018$, pp. 101-118.

5 Balances de los resultados obtenidos por los documentales cubanos en festivales internacionales pueden ser encontrados en: Alfredo Guevara, “Cine Cubano 1963”, Alfredo Guevara, Revolución es Lucidez, La Habana, Ediciones ICAIC, 1998, pp. 111-122; Alfredo Guevara y Raúl Garcés, Los años de la ira. Viña del Mar 67, La Habana, Ediciones Nuevo Cine Latinoamericano, 2007.

6 Lloga, op. cit. 2018.

7 Sánchez, op. cit.; Carlos Guillermo Lloga, "La hermenéutica ontológica como estrategia de interpretación de la realidad por el cine documental cubano de los años sesenta", Tesis para optar al grado de Máster en Estudios Cubanos y del Caribe, Santiago de Cuba, Universidad de Oriente, 2015. 
aunque contó con diferentes corrientes estéticas, apostó por el montaje asociativo ${ }^{8}$, el empleo de la música no-diegética, la voz-en-off y el uso de efectos especiales visuales y sonoros, como características sobresalientes. Desde un punto de vista temático, es la variedad el rasgo fundamental; así como la capacidad para establecer un diálogo con los discursos políticos que circularon dentro y fuera del país. Es el único momento en la historia del cine cubano donde el documental ha sido el centro de la atención de la cultura cinematográfica en la Isla. Cineastas como Santiago Álvarez, Sara Gómez, Nicolás Guillén Landrián, Octavio Cortázar, José Massip y Bernabé Hernández se destacan como figuras representativas de los "felices sesenta".

Los setenta, en cambio, trajeron consigo un endurecimiento de la política cultural. ${ }^{9}$ Fueron tiempos marcados por el aislamiento internacional del país y el distanciamiento por parte de la comunidad intelectual global que se había declarado aliada de la Isla en años anteriores. Hacia el interior, el aumento de las tensiones ideológicas en el campo de la cultura tuvo un hecho sobresaliente en el Primer Congreso de Educación y Cultura, celebrado en 1971; donde se trazaron las líneas fundamentales que definieron la política cultural cubana en los años siguientes. Unos cuantos investigadores referencian las sendas críticas a la gestión del ICAIC (fundamentalmente en la exhibición) efectuadas por funcionarios del Partido Comunista de Cuba (PCC) y el sector de educación. ${ }^{10}$ Si bien Fornet ${ }^{11}$ defiende que las presiones sobre la gestión cultural no afectaron directamente al cine; otros, 12 por el contrario, apuntan el aumento de la temática histórica y la voluntad didáctica en los documentales producidos en los años posteriores al Congreso. En relación a la exuberancia y actitud problematizadora que tipificó el documental de la primera década del ICAIC, los setenta evidencian "la pobreza de una temática de indagación social" y la "carencia de las búsquedas experimentales en el lenguaje cinematográfico."13

La fundación del Ministerio de Cultura en 1976 trajo consigo nuevas transformaciones y provocó un relajamiento en el dogmatismo de la política trazada desde el Congreso. Para Fornet, el ministerio supuso el fin de lo que llama el "Quinquenio Gris."14 La reorganización de la gestión institucional de la cultura en la segunda mitad de los setenta también tuvo influencias en el rango de acción de los cineastas. Ello es perceptible fundamentalmente en las temáticas abordadas. Marina Ochoa plantea que: "Si bien en los 70 había un clima paralizador, ya en 1978 había habido una suerte de distensión (...)"15

La literatura sobre cine cubano muestra una progresiva desatención al documental en la misma medida que se aleja cronológicamente de los años sesenta. De igual manera, es evidente que el género se distancia del núcleo de atención de la producción fílmica del ICAIC, ahora más

\footnotetext{
8 Aunque se pueden citar ejemplos de documentales participativos en los sesenta, como En la otra Isla (1968) de Sara Gómez, la estética que particulariza el género en este periodo celebra el potencial expresivo del montaje.

${ }_{9}^{9}$ Ambrosio Fornet, Las trampas del oficio. Apuntes sobre cine y sociedad, La Habana, Ediciones ICAIC, 2017.

10 Por ejemplo: Mario Naito, "El documental cubano en la década del setenta”, Armando Pérez (ed.) El cine, el crítico y el espectador que vino a cenar. Memorias del XVIII Taller Nacional de Crítica Cinematográfica, Santiago de Cuba, Editorial Oriente, 2013, p. 43; Del Río, op. cit. p. 224.

11 Fornet, op. cit., p. 55.

12 Naito, "El documental cubano en la década del setenta", p. 44, y Del Río, op. cit. p. 224.

13 Naito, "El documental cubano en la década del setenta", p. 48.

14 Fornet, op. cit., p. 55.

15 Marina Ochoa, “Los años 80: ¿El gran espejismo?”, 2007, Recuperado el 21 de abril de 2016, de La Pupila Insomne: MARINA OCHOA SOBRE EL DOCUMENTAL DEL ICAIC EN LOS 80 _ cine cubano, la pupila insomne.htm
} 
enfocado en alcanzar resultados notables en el campo de la ficción. En consecuencia, la no-ficción fue relegada a cumplir encargos mediáticos del Estado-nación y la capacidad vanguardista y de ruptura formal que experimentó en la primera década posterior a la fundación del Instituto de cine se desvaneció.

Específicamente, en relación al contexto documental de los ochenta se observa una tendencia a cualificar la época a partir de variables asociadas a la ficción y extrapoladas acríticamente al documental. Por ejemplo, Sara Vega y Mario Naito expresan que:

Poco más de sesenta largometrajes cubanos, entre ficción y documentales, fueron estrenados durante los años ochenta, el mayor número de cintas cubanas estrenadas en una década hasta esa fecha. En ello influyó notablemente el debut en la ficción, entre 1984 y 1985, de una nueva generación de realizadores provenientes del documental. En su mayoría, estas películas tendían a cuestionar la realidad cotidiana por medio del humor y recibieron una favorable respuesta del público, aunque hubo quienes consideraban que el cine nacional había perdido su aliento creador a favor de un crecimiento en cantidad y popularidad. ${ }^{16}$

Nótese que, si bien las cifras manejadas corresponden tanto a ficción como a no-ficción, la valoración cualitativa de las mismas se concentra sólo en la primera, dejando el género documental circunscrito dentro de un único juicio. Asimismo, mientras que con respecto a las décadas anteriores es posible encontrar estudios diferenciados de épocas, estéticas y poéticas autorales, los ochenta son definidos por las transformaciones institucionales que se sucedieron en el ICAIC y su impronta en los textos fílmicos, un alto enfoque en las dinámicas de los contenidos y la omisión rampante del estudio de los recursos formales empleados por el mismo. El presente artículo propone una relectura del género documental al considerar que en esta etapa se desarrollaron elementos estéticos poco vistos anteriormente. Se concentra en la producción del ICAIC, dejando de lado otros productores actuantes en la Cuba del mismo periodo. ${ }^{17}$ Primeramente, se analizan las coyunturas del cambio estético e ideológico entre los setenta y los ochenta demostrando que el año 1979 resulta marca crucial que inicia una nueva etapa. A continuación se exploran los sub-géneros desarrollados en los ochenta tomando en consideración la clasificación propuesta por Aufderheide. ${ }^{18}$ Luego, se examinan la crítica social, el humor y la sinergia entre ficción y no-ficción como variables que contribuyen a evaluar los recursos cinematográficos desplegados por el documental de los ochenta. El artículo aspira a establecer nuevos criterios que permitan una relectura del género, revalorizándolo a partir de los múltiples usos de la performatividad explotados por el documental de aquel momento.

\section{Un año bisagra para la cinematografía cubana: 1979}

\footnotetext{
16 Sara Vega y Mario Naito, Cartelera cinematográfica cubana (1960-2017), Santiago de Cuba, Editorial Oriente, 2018, p. 26, la cursiva nos pertenece.

17 Para un análisis detallado del descentramiento de la producción mediática en Cuba durante los ochenta véase Ann Marie Stock, On location in Cuba. Street filmmaking during times of transition, North Carolina, The University of North Carolina Press, 2009; y Carlos Guillermo Lloga, “La construcción de la imagen local en los documentales producidos en el oriente de Cuba (1986-2016)", Tesis para optar al grado de Doctor en Film Studies and Visual Culture, Universidad de Amberes, 2019.

18 Patricia Aufderheide, Documentary film. A Very Short Introduction, Oxford, Oxford University Press, 2007.
} 
Luego de 1978 se inició una corriente en la que los filmes abordaron temas anteriormente inhibidos. Una de las obras que refleja esta pronta transformación en el documental fue la película 55 Hermanos (1978) de Jesús Díaz. Este filme se aproxima a la llegada a Cuba de un grupo de jóvenes que fueron sacados del país al triunfo de la Revolución. El documental claramente muestra un tema sensible para la sociedad cubana. La representación en pantalla de sucesos considerados tabú en el ámbito del discurso público nacional abrió una brecha para que, desde el arte, se mantuviera una visión activa de disímiles cuestiones del acontecer social y político. Es un filme testigo del breve período de acercamiento entre Cuba y los Estados Unidos acaecido bajo la presidencia de Jimmy Carter. En una cuerda diferente, en este mismo año se realizó El piropo de Luis Felipe Bernaza, película importante para el desenvolvimiento del género en la etapa siguiente, ya que con este material comenzó el rescate progresivo del humor como estrategia retórica en el cine documental cubano.

De acuerdo con diversos investigadores de cine cubano, el año 1979 se presenta como punto decisivo en la transformación de la producción cinematográfica del país. ${ }^{19}$ La incidencia de disímiles circunstancias coadyuvó en ese resultado. Una de las más importantes fue la creación del Festival del Nuevo Cine Latinoamericano, la cual propició la confluencia de múltiples figuras de toda América Latina. Los extensos debates en seminarios y talleres dentro del marco del festival influyeron en el advenimiento de profundas variaciones tanto en la política cultural, como en la narrativa y el uso del lenguaje cinematográfico.

Figura 1. Comportamiento de la producción documental del ICAIC de 1979 a 1982. Elaboración de los autores a partir del catálogo Producciones del Instituto Cubano de Arte e Industria Cinematográfica ICAIC 1959-2004.

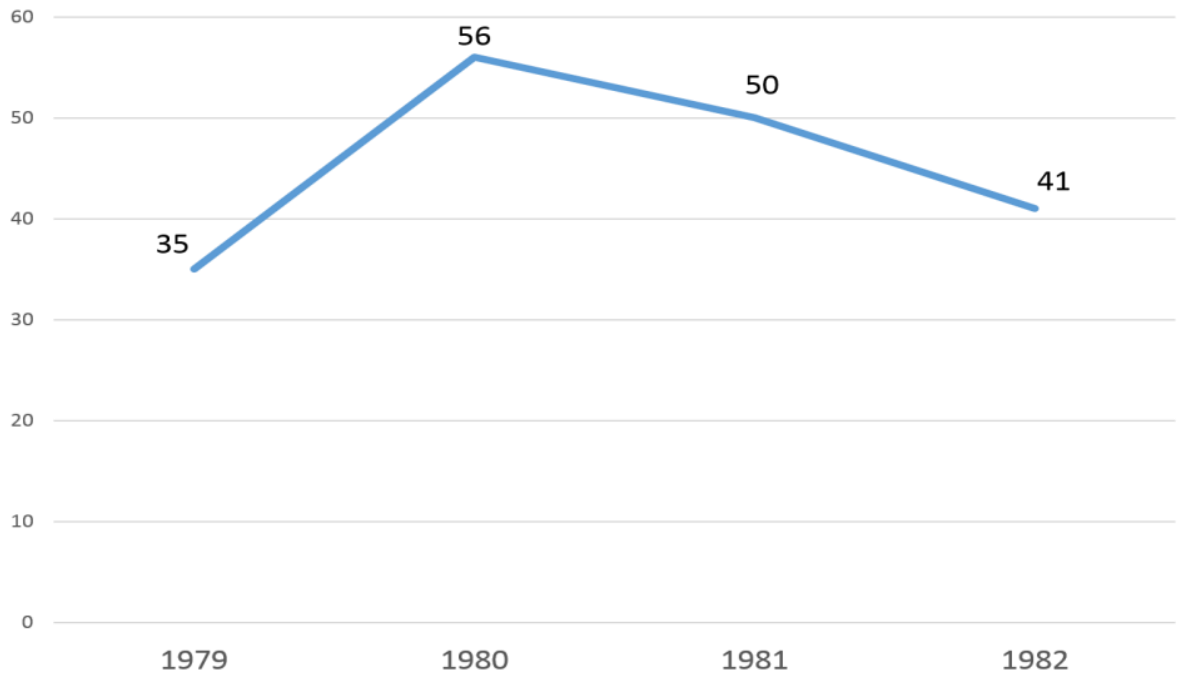

A partir de este año ocurre un aumento en la producción del cine documental y el crecimiento estable del volumen de obras creadas es un rasgo particular de la etapa que recién comenzaba (Figura 1). También se experimenta una ampliación en la variedad de contenidos. Ello es apreciable al revisar varios filmes de 1979, como Carteles son cantares y Como quiera canto yo

19 Ver Chanan, op. cit. y Claudia González Machado, El Riesgo de la Herejía. Cartografía de la Crítica y el discurso Fílmico en la revista Cine Cubano (1960-2010), La Habana, Ediciones ICAIC, 2013. 
de Constante Rapi Diego, Contrastes y Libertango de Héctor Veitía, El danzón de Oscar Valdés, Psicoballet de Sergio Núñez, así como Cultivando la piedra y Los Karatecas de Santiago Villafuerte.

De este conjunto sobresalen dos obras pilares: Redonda y viene en caja cuadrada de Rolando Díaz y Wifredo Lam de Humberto Solás. El primero evidencia la mirada a temas populares como el béisbol mediante el humor. Jorge Luis Sánchez expresa que este material provocó un "punto de giro" con respecto al tratamiento de los filmes relacionados con el deporte. El segundo es un material de corte biográfico con una alta dosis de puesta en escena construida, elemento novedoso en el documental de entonces. El crítico Rolando Pérez Betancourt destaca la importancia de la fotografía en esta obra y los intentos de reproducir, desde la imagen cinematográfica, una equivalencia visual con la proyección plástica del pintor tratado. Wifredo Lam se coloca justo en centro de la tensión referida por Bruzzi de considerar al documental como registro o como representación. El filme de Solás abrió las puertas de la performatividad para el documental cubano.

Figura 2. Cantidad de emisiones del Noticiero ICAIC Latinoamericano que incorporan crítica social. Elaboración de los autores a partir de los datos provistos por Ochoa.

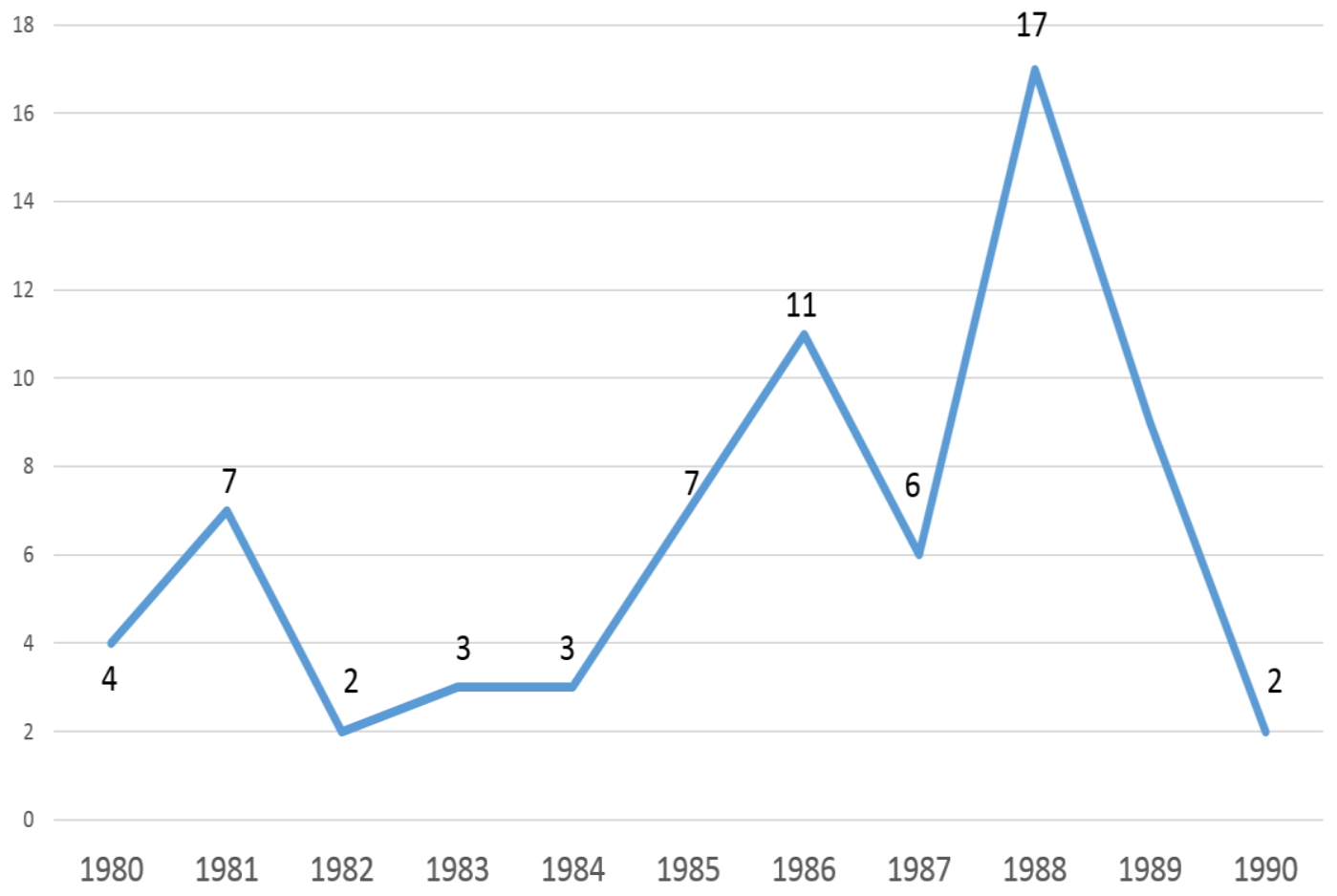

El Noticiero ICAIC Latinoamericano fue una de las áreas donde los síntomas de cambio se experimentaron de una manera más clara. Según los datos brindados por Marina Ochoa, ya desde 1977 aparecieron dos noticieros con matices de crítica social, el 806 y 821, dirigidos ambos por Daniel Díaz Torres. A partir de la entrada en los años ochenta se hace más habitual esta perspectiva (Figura 2). Los realizadores fueron Daniel Díaz Torres, Rolando Díaz, Francisco 
Puñal, Lázaro Buría, Luis Felipe Bernaza, Idelfonso Ramos, Melchor Casals, Héctor Veitía, Vivian Argilagos y José Padrón. Emisiones como La ventana, La venta de flores, Los escombros, Los baches de las calles de La Habana, son algunos de los más célebres. Jorge Luis Sánchez plantea que estos cortos noticiosos "(...) se convirtieron en quebraderos de cabeza para la burocracia indolente, en pánico si aparecían como blancos."

El ambiente de renovación que comenzaba por entonces tuvo su punto de giro definitivo unos años después, en 1982, a partir del cambio de la dirección del ICAIC. Con la sustitución de Alfredo Guevara por Julio García Espinosa se llevó a cabo una transformación en las metodologías del trabajo dentro de la institución. El principal resultado fue la búsqueda de un cine que lograra una conexión más estrecha con los públicos, de ahí su carácter popular. Tal premisa, estudiada sobre todo a partir de los largometrajes de ficción, también permeó otros géneros producidos por el Instituto de Cine. La evidencia sugiere que la industria cubana se comportó de forma muy dinámica desde el inicio de la década del ochenta y a la vanguardia de esta vitalidad se mantuvo el género documental.

\section{Sub-géneros del documental de los ochenta}

Desde la teoría cinematográfica, la literatura que se aproxima a los géneros del documental proyecta sus concepciones a partir de una mixtura entre convenciones estilísticas (narrativas y visuales), temáticas e institucionales. En este estudio, se utilizó la clasificación ofrecida por Patricia Aufderheide en Documentary Film. A Very Short Introduction. La autora propone seis categorías: asuntos públicos, propaganda gubernamental, defensor, histórico, etnográfico y de la naturaleza. Para Aufderheide, esta clasificación responde a una evaluación del devenir histórico del documental y se encuentra ligada a la función desempeñada por los filmes a nivel social, por lo que las distinciones propuestas no incluyen solo elementos cinematográficos. Con ello, su sistema se separa de otros como el de Keith Beattie, ${ }^{20}$ el cual combina categorías propias del cine como el cine directo/cinema verité, convenciones narrativas como el documental autobiográfico y formas institucionales alternativas como las producciones autóctonas, entre otras ${ }^{21}$. También se diferencia de propuestas como la célebre tipología de Nichols, quien llamó sub-géneros a sus propuestas de clasificación documental ${ }^{22}$ en Introduction to documentary 1st Edition (2001). ${ }^{23}$

El modelo de Aufderheide, además de referirse a la vida social del cine, supone un relativo constreñimiento de las temáticas abordadas por las películas. Es decir, aunque un filme de la

\footnotetext{
${ }^{20}$ Keith Beattie, Documentary screens: Non-fiction film and television, New York, Palgrave Macmillan, 2004.

${ }^{21}$ La clasificación total de sub-géneros propuesta por Beattie está compuesta por: filme etnográfico, cine directo y cinema verité, documental autobiográfico, drama-documentary y documentary drama, producciones documentales autóctonas, filmes compilación y periodismo documental televisivo.

22 Las categorías de Nichols son: documental expositivo, de observación, participativo, performativo, poético y reflexivo.

23 Ello constituye una novedad de esta edición, pues en La representación de la realidad (Barcelona, Paidós, 1997), Nichols llamó a su esquema "modalidades de representación". Incluso, en la segunda edición de Introduction to documentary (Bloomington, Indiana University Press, 2010), abandona la idea de los sub-géneros (aunque se mantiene implícita) y retoma los términos "modos", "modalidades" o incluso otros más abstractos como "prototipos". En cualquier caso, la idea de Nichols se halla asociada a formas retóricas del discurso del documental y dentro de los documentary studies es más conocida como modalidades que como sub-géneros.
} 
naturaleza, por ejemplo, puede abordar cualquier tópico específico, parece claro que la categoría prioriza la promoción de ciertos asuntos. Para el caso de las películas sobre la naturaleza, la protección ambiental o la observación de las especies lucen como contenidos privilegiados.

Como en todo encasillamiento, no más son planteadas las clases para que surjan numerosos casos que no se ajustan a ella. La clasificación se vuelve compleja en los argumentos en los que hay una voz autoral mucho más evidente y al notar que la esteticidad de la película se halla en un plano tanto o más destacado que su referencialidad al mundo histórico. En esta investigación, además del ordenamiento de Aufderheide, se consideró una categoría más: el documental biográfico.

En Cuba, durante los ochenta fueron realizadas muchas películas dedicadas a figuras relevantes de la historia política y la cultura nacional. Estos filmes deben ser comprendidos como filmes históricos debido a que su premisa se apoya fundamentalmente en la utilización de material de archivo (fotografías y recortes de prensa) y el argumento de especialistas como mecanismos de "recuperación" del pasado y principal recurso evidencial de los filmes. En esta cuerda se destacan: Con la misma pasión (1980, Rapi Diego, sobre el célebre cantante Benny Moré); Mariano (1980, Marisol Trujillo); Barbarito Diez (1983, Santiago Villafuerte). Rita (1980), Lecuona (1983), Marinello (1983), María Teresa (1984) y Roldán y Caturla (1985), de Oscar Luis Valdés.

Otras obras que comparten clasificación, pero que desarrollan mayor complejidad en su realización, son: A veces miro mi vida (1981, Orlando Rojas); Omara (1983, Fernando Pérez); Yo soy la canción que canto (1985, Mayra Vilasís); En Guayabero, mamá... Me quieren dar (1986, Octavio Cortázar); Buscando a Chano Pozo (1987, Rebeca Chávez) y Kid Chocolate (1987, Gerardo Chijona). Estos filmes con frecuencia incluyen otras herramientas formales como la performatividad en apoyo a la estructura del filme.

A pesar de que las películas mencionadas se enfocan en la vida de sus personajes, es importante resaltar que este estudio hace una distinción entre el documental histórico y documental biográfico. En esta misma época también se produjeron en Cuba obras que abordan personajes comunes, siguen su vida cotidiana y muestran las particularidades de sus relatos personales. Tales filmes son las obras comprendidas en esta investigación como documentales biográficos. Esta tipología, según Aitken, sostiene su discurso narrativo en los testimonios de los personajes y comienza a ser popular a nivel global luego de los años setenta, influidos sobre todo por la filosofía del movimiento de la Nueva Historia. ${ }^{24}$ Dentro del ICAIC, fueron numerosos los títulos que asumieron esta perspectiva, pero entre ellos se destacan: Cayita, una leyenda (1980) y Pedro cero por ciento (1980), de Luis Felipe Bernaza; Mujer ante el espejo (1983, Marisol Trujillo) y A cielo abierto (1987, Santiago Villafuerte).

El documental del ICAIC de los ochenta se acercó a una gran variedad de tópicos. Existió una mayor propensión al desarrollo de argumentos concernientes a los 'asuntos públicos'. Los temas preferidos son: la corrupción, la burocracia, la prestación de malos servicios a la población, las cuestiones de género y el embarazo en la adolescencia. Aquí podemos encontrar filmes como El eslabón más fuerte (1980), de Rigoberto López, Historia de una descarga (1981) y Escenas en contenedores (1988), de Melchor Casals, Mientras el río pasa (1986), Volvamos a empezar (1987) y Desde lejos (1989), de Guillermo Centeno y Un pedazo de mí (1989) y El fanguito (1990) de Jorge Luis Sánchez. A partir de este continuo interés por los asuntos públicos es posible identificar un

24 Ian Aitken, The Concise Encyclopedia of the Documentary Film, New York, Routledge, 2013, p. 13. 
cambio de mentalidad que se manifiesta entre los cineastas cubanos, fundamentalmente de los documentalistas.

Es importante reconocer, sin embargo, que la variedad que se vive en estos años no supuso un rompimiento con las tendencias de etapas anteriores. Más bien, una ampliación de las perspectivas empleadas y un reposicionamiento de su relevancia. Si en los setenta, el documental de 'propaganda gubernamental' fue la prioridad de la industria, en la década siguiente, sin abandonar su puesto privilegiado, la diferencia con otros sub-géneros, en cuanto a cantidad de obras e importancia de las mismas, fue renegociada; coyuntura que propició la impresión de pluralidad que define a los ochenta en Cuba.

En este decenio el documental de 'propaganda gubernamental' se entremezcla con el documental 'defensor'. El alto centralismo de la institucionalidad cubana provoca que la frontera entre una taxonomía y otra se torne difusa. A pesar de que estas dos denominaciones abarcan temas muy similares, de acuerdo con Aufderheide, lo que distingue a ambas clases es la diferencia que existe en la naturaleza de los auspiciadores del material audio-visual. Los documentales de propaganda generalmente son herramientas de persuasión promovidas por la estructura de gobierno. Por otra parte, los defensores funcionan como instrumentos de organizaciones sociales para promover sus perspectivas. ${ }^{25}$ Ejemplos de este tipo son: Habana vieja (1982, Oscar Luis Valdés) y Nace una escuela (1987, Melchor Casals).

En el período que se estudia, la proyección de Cuba en el ámbito internacional estuvo definida por una intensa campaña de solidaridad con el Tercer Mundo. Son años de una constante colaboración con países de América Latina, Asia y África y que tienen su epítome en la participación de Cuba en la guerra de Angola. El cine de propaganda gubernamental constituyó el rostro mediático de esta proyección y produjo un amplio catálogo relacionado con el tema: Santiago Álvarez realizó El desafí (1979), La cumbre que nos une (1979) y Comenzó a retumbar el Momotombo (1981); Jesús Díaz dirigió En tierra de Sandino (1980); Víctor Casaus hizo Granada: pequeño país, gran revolución (1980); Rolando Díaz realizó Quincho Barrilete (1980) e Idelfonso Ramos dirigió Belice (1981), entre otros.

\section{Clave 1: La crítica social}

La crítica social fue una novedad en el documental de los ochenta. Después de haber sido prácticamente desterrada de la esfera pública luego de 1971, esta reapareció paulatinamente, como se vio más arriba, en diversos formatos de la no-ficción y desde nuevas aristas temáticas. ${ }^{26}$ Para el investigador Joel del Río, esta tendencia encarna el afán de confrontar la realidad desde facetas conflictivas desarrollando puntos de vista escasos o incluso ausentes en las formas tradicionales de los medios públicos. ${ }^{27}$

En primer lugar, una corriente se orientó hacia las situaciones inoperantes de la realidad. Fueron diversos los filmes que tienen como premisa el reproche hacia la burocracia y la mala calidad de las producciones y los servicios. Muchos son los títulos que evidencian esta tendencia: Despilfarro (1981), Historia de una descarga (1981) y Escenas en contenedores (1988), de Melchor

${ }^{25}$ Aufderheide, op. cit., p. 77

26 Ochoa, op.cit.

${ }^{27}$ Joel del Río, "La generación intermedia del cine cubano y la comedia popular", Edgar Soberón (ed.) Los cines de América Latina y el Caribe. Parte 2, San Antonio de los Baños, Ediciones EICTV, 2013, p. 148. 
Casals; Tiempo libre a la roca (1981) y Taller de la vida (1985, Santiago Álvarez); ¿Qué tú crees? (1986, Mario Crespo); La espera (1983, Orlando Rojas); Controversia (1981, Rolando Díaz); Se lo lleva el viento (1985, Idelfonso Ramos); Ella vendía coquitos (1986, Gerardo Chijona); Propiedad social (1986, Sergio Núñez); Estética (1984), Vecinos (1985) y Chapucerías (1987), de Enrique Colina.

Es necesario destacar el caso particular de Yo también te haré llorar (1984, Enrique Colina). La literatura sobre cine cubano legitima a este director como el documentalista más destacado de los ochenta. ${ }^{28}$ Es un documental participativo en el que la autoridad textual se desplaza hacia los actores sociales. Los testimonios de los individuos entrevistados son engarzados siguiendo como argumento las incapacidades de gestión laboral. Yo también te haré llorar, presenta un montaje discontinuo, en el que las imágenes se vinculan por contraste.

En segundo lugar, otra cuerda en la que se encauzó la crítica social corresponde al tratamiento de temas concernientes al género. En la cinematografía cubana no había ocurrido antes tal eclosión de películas en las que se analizara este tópico, mucho menos con la riqueza en que se dio. Algunos títulos importantes sobre esta arista son: Un trabajo cotidiano (1980, Manuel Herrera); Controversia ${ }^{29}$ (1981, Rolando Díaz); Mujer ante el espejo (1983) y Mujer junto al faro (1984), de Marisol Trujillo30; Mamá se va a la guerra (1984, Guillermo Centeno); Cuando una mujer no duerme (1984) y Una más entre ellos (1988), de Rebeca Chávez; Es quererte decir (1985, Miriam Talavera); ¿Mujeres dirigentes? (1985, Bernabé Hernández); Ella vendía coquitos (1986, Gerardo Chijona); Campeonas (1988, Oscar Luis Valdés) y Esa mujer de tantas estrellas (1988, Mayra Vilasís). Como característica esencial de esta etapa se distingue la presencia de mujeres realizadores en la industria cubana. En los ochenta irrumpen Marisol Trujillo, Mayra Vilasís, Miriam Talavera, Rebeca Chávez, Gloria Rolando, entre otras. ${ }^{31}$

En tercer lugar, la crítica social encontró otro nicho en el tratamiento de temas como la sexualidad en los jóvenes y el embarazo precoz. De acuerdo con el investigador Jorge Luis Sánchez este es "uno de los grandes síntomas de cómo ha evolucionado la sociedad cubana en la década." 32 Se produjeron películas como: Pensando en el amor (1980) y Sexus (1981), de Melchor Casals; Castillos en el aire (1986, Rebeca Chávez) y En el nombre del hijo (1986, Santiago Villafuerte).

Un ejemplar destacado de esta tipología es No es tiempo de cigüeñas (1987, Mario Crespo). En el mismo, mediante el empleo de la performatividad, se desenvuelve una trama dramatizada a la que son acopladas entrevistas a través de un montaje paralelo. Es importante resaltar que Crespo utilizó dos soportes de grabación: $35 \mathrm{~mm}$ para las dramatizaciones y el video para los testimonios. Hay una mise-en-scène mixta, que combina una escenografía construida en las

28 Juan Antonio García Borrero, “Vecinos”, Paulo Antonio Paranaguá (ed.) Cine Documental en América Latina, Madrid, Ediciones Cátedra, pp. 387-388; y Chanan, op. cit.

${ }^{29}$ Esta obra aborda el tema de la doble jornada en el trabajo de la mujer (trabajo social y atención al hogar), suscita el debate sobre la igualdad entre el hombre y la mujer.

${ }^{30}$ Marisol Trujillo es una de las documentalistas más comprometidas con las imágenes de mujeres. A ella pertenecen gran cantidad de obras efectuadas en estos años como: A escena (1981), Encuentro (1981), Fumando espero (1982), Canción feliz (1983), Oración (1984), entre otros. Su documental más reconocido fue Mujer ante el espejo, que muestra a la bailarina Rosario Suárez (Charín), y sus sacrificios por el éxito en la vida profesional, incluyendo el ferviente cuidado su cuerpo. La investigadora Danae Diéguez plantea que "cuando la bailarina decide salir embarazada y esforzarse para continuar después con su carrera, se observa una de las secuencias más interesantes del documental. En una sucesión de planos, la niña llora desde la cuna, en la cocina ella hierve los pomos, la lavadora se desborda y en el estudio el esposo (padre) lee y escribe." Danae Diéguez, "Cine de mujeres en Cuba”, Luciano Castillo et al., op. cit., p. 157.

31 Véase Danae Diéguez, Ibíd., p. 155.

32 Sánchez, op. cit. p. 298. 
escenas actuadas, con espacios en su estado natural. La narración se desarrolla a través de un sistema estilístico en el que no hay una jerarquía clara entre ninguna de las dos estructuras; ello constituye un elemento novedoso, pues el género documental tiende a trabajar con escenografías existentes.

De igual manera, No es tiempo de cigüeñas muestra una iluminación dura y proveniente desde una dirección lateral lo que acentúa los rasgos en el rostro de los entrevistados, llegando en ocasiones a extremos donde no se distingue la fisonomía de los mismos. Tal recurso ofrece sensación de privacidad a las escenas e intensifica el tono de sus comentarios. La abundancia de los planos en detalle acrecienta la introspección psicológica del filme. La ficcionalización del discurso en este documental es un ejemplo cardinal de la tendencia hacia la performatividad que dominó en la estética de la no-ficción del ICAIC en esta etapa.

\section{Clave 2: El Humor}

A diferencia de la clave anterior, el humor no está exclusivamente asociado a la temática de las obras. No es un fin en sí mismo, sino una articulación de estrategias retóricas (visuales y narrativas) a través de las cuales se canalizó la crítica social. Durante los ochenta, la atención a historias cotidianas y la comedia fueron dos de los mecanismos desarrollados por el ICAIC en busca de una mayor popularidad de su creación cinematográfica. ${ }^{33}$ Michael Chanan apunta cómo varios largometrajes de ficción dirigidos por jóvenes cineastas legitimaron la nueva política de producción llevada a cabo por entonces. ${ }^{34}$ Se permuta (1983, Juan Carlos Tabío), Los pájaros tirándole a la escopeta (1984, Rolando Díaz) y Una novia para David (1985, Orlando Rojas), ejemplifican esta tendencia.

Resulta muy interesante que la inclinación hacia el humor también haya tenido amplio calado en la documentalística de la época. La estrecha relación que construye el género con respecto a la realidad profílmica que aborda y la tradición de vínculo con problemáticas sociales, convierten al documental en un vehículo de concienciación más cercano al involucramiento político que a la distensión y relajamiento de la comedia. Nada ejemplifica más esta tradición que la metáfora de Nichols, al asociar el documental con lo que llama "discursos de sobriedad". 35

Sin embargo, el documental cubano de los ochenta logró generar formas novedosas de acercamiento a sus circunstancias sociales. La conexión con la audiencia desde la comedia se edifica a partir de un vínculo emotivo, más que racional, de ahí que Marina Ochoa considere que, en esta etapa, "el humor no es utilizado para distanciarse sino para involucrarse." 36 En tal cuerda se encuentran obras como: La importancia universal del hueco (1981, Santiago Álvarez); Del uno al diez (1982) y Para gustos se han hecho los colores (1982, Rolando Díaz). Mención aparte merecen Estética (1984), Vecinos (1985) y Más vale tarde que nunca (1986), de Enrique Colina. Según Paranaguá, sus obras logran "reivindicar el tipo de documental convencional, el filme didáctico con una dosis de humor corrosivo." 37

33 Marta Díaz y Joel del Río, Los cien caminos del cine cubano, La Habana, Ediciones ICAIC, p. 59; Del Río, op. cit. 2017, p. 227.

${ }^{34}$ Chanan, op. cit.

35 Bill Nichols, op. cit. 1997, p. 32.

36 Ochoa, op. cit.

37 Citado en Chanan, op. cit. p. 425. 
En el caso particular de Vecinos, el realizador registra los roces de la convivencia en un edificio multifamiliar. En entrevista al reconocido director cubano Melchor Casals, el documental “(..) expone a los ruidosos y despreocupados. Su estilo se deriva de asociar libremente fragmentos breves de escenas observadas, entrevistas, segmentos de filmes famosos, y canciones populares añadidas en la banda sonora." 38 Es posible decir, además, que esta obra constituye el resultado de un meditado trabajo cinematográfico, que apela con astucia a las posibilidades expresivas del montaje, el sonido y sobre todo a la música (a veces diegética y otras no diegética), insertada no de modo incidental sino con función de interlocutor en sí misma.

Otra de las vías en las que se manifestó el humor en el documental de los años ochenta fue mediante la distensión de la densidad de los temas. En particular, el filme biográfico, abundantemente representado desde inicios de la década asumió un distintivo carácter jovial. Este es el caso de Cayita, una leyenda (1980) y Pedro cero por ciento (1980), de Luis Felipe Bernaza; La autobiografía según Virulo (1981, Héctor Veitía); En Guayabero, mamá... Me quieren dar (1986, Octavio Cortázar); Yo soy Juana Bacallao (1989, Miriam Talavera). Con ello, se disminuyó el tono solemne que caracteriza este sub-género, al tiempo que promueve una dinámica narrativa más cercana a la cotidianeidad.

\section{Clave 3: Sinergia entre los géneros}

El tercer rasgo fundamental de la producción documental del periodo es la marcada sinergia establecida entre los géneros de ficción y documental. Ello no es precisamente una cualidad novedosa del cine cubano del ICAIC, varias de las obras de ficción más destacadas de los sesenta y setenta se apoyan en recursos provenientes del documental. Memorias del subdesarrollo (1968, Tomás Gutiérrez Alea), La primera carga al machete (1969, Manuel Octavio Gómez) y De cierta manera (1974, Sara Gómez), por solo mencionar algunos, ejemplifican con claridad la relevancia de esta tendencia que Fornet considera un elemento cardinal de la cinematografía del ICAIC. ${ }^{39}$ Sin embargo, durante los ochenta se desarrolló un interesante vínculo en reversa, es decir, esta vez fue el documental el que asume con desenfado formas y técnicas más comunes en la ficción.

Esta correlación estuvo dada por diversas circunstancias, entre las que se destaca el desenvolvimiento de los realizadores en ambos géneros al unísono. En este lapso emerge una promoción de cineastas que, aunque ha sido reconocida fundamentalmente por su exitoso debut en la ficción, se mantuvo activa en la realización de documentales. Figuras como Jesús Díaz con En tierra de Sandino (1980); Orlando Rojas con A veces miro mi vida (1981) y La espera (1983); Fernando Pérez con Las armas invisibles (1981), Camilo (1982) y Omara (1983); Enrique Pineda Barnet con Ensayo romántico (1985); Luis Felipe Bernaza continúa en la documentalística ${ }^{40}$ luego de haber incursionado en la ficción. Incluso Santiago Álvarez, quien en esta década realiza su único filme de ficción, Los refugiados de la cueva del muerto (1983), continúa dirigiendo documentales posteriormente. Además, otros cineastas de reconocida trayectoria trabajan en la

\footnotetext{
38 Susan Fanshel, A Decade of Cuban Documentary Film, New York, Young Filmmakers Foundation, p. 21.

${ }^{39}$ Fornet, op. cit.

40 Tiene títulos como Médico de todo (1987).
} 
no-ficción, como Humberto Solás que realiza el ya mencionado Wifredo Lam (1979) y, posteriormente, Obataleo (1988).

Es importante agregar que en esta etapa algunas obras documentales luego devinieron filmes de ficción. El largometraje De tal Pedro tal astilla (1985) proviene del documental Pedro cero por ciento (1980), de Luis Felipe Bernaza. Los mismo sucedió con otras películas como Jíbaro (1984, Daniel Díaz Torres ${ }^{41}$ ) y El corazón sobre la tierra (1985, Constante Rapi Diego), ambas antecedidas por documentales producidos en 1982.

Ahora bien, en el núcleo de la estrecha asociación con la ficción acaecida en el documental de estos años se encuentra la performatividad. Diversos investigadores han señalado el auge global de esta corriente en las últimas dos décadas del siglo veinte. ${ }^{42}$ En consecuencia, es posible señalar una alineación del documental del ICAIC con las corrientes contemporáneas en el marco internacional. De acuerdo con Nichols, entre las modalidades del género, es esta la que despliega una mayor ficcionalización de los eventos de la realidad que inquiere. ${ }^{43} \mathrm{El}$ filme performativo tiene su fundamento en la puesta en escena; ya sea a través del uso de actores para presentación de sucesos históricos o del registro de acciones que en sí mismas son representadas para una audiencia diegética. La investigadora Stella Bruzzi asevera que "el documental performativo utiliza las escenificaciones dentro del contexto de la no ficción para quitarle atención a las imposibilidades de representar auténticamente." 44

En el caso particular del documental cubano, la performatividad asume tres manifestaciones. En primer lugar, es posible identificar una performatividad reactiva, presente en los documentales dedicados a las personalidades de la cultura nacional y en los que se registra su modo de actuación (Figura 3). En estas películas es perceptible una fotografía que sigue (se subordina) a los acontecimientos. Un ejemplo es el documental Omara (1983, Fernando Pérez), donde el director se beneficia de una de las grabaciones en estudio de la cantante para "evidenciar" el talento de la protagonista al espectador.

Figura 3. Formas ficcionales presentes en el documental cubano de los años ochenta.

41 A este realizador se le deben las obras Madera (1980), Los dueños del río (1980), Vaquero de la montaña (1982), y Crónica informal desde Caracas (1989). Debe recordarse también que fue el autor de la película Alicia en el pueblo de Maravillas (1990), que provocó una de las mayores polémicas del cine cubano finalizando esta década. Además, se debe resaltar que el documental Jíbaro constituye un material vital dentro de la cinematografía de los ochenta ya que su estructura no recae sobre la entrevista. La composición se caracteriza por lograr encuadres en los que se capta una atmósfera más cercana a las que se representan en los largos de ficción.

42 Véase Bruzzi, op. cit.; Aufderheide, op. cit.; y Nichols, op. cit., 2010.

43 Nichols, ídem.

44 Bruzzi, op. cit. p. 186. 
(1) Performatividad reactiva

(2) Performatividad proactiva

(3) Performatividad evidencial
Recoge el accionar de individuos naturalmente performáticos. El documental es un registro pasivo de un evento. Ejemplo. Omara (1983, Fernando Pérez)

Movilización de la realidad en función de su registro cinematográfico. Los personajes reproducen su quehacer exclusivamente para el filme. La observación fílmica es núcleo activo con respecto a los eventos. Ejemplo: La espera (1983, Orlando Rojas)

Separación entre el plano visual y el sonoro. El discurso hablado guía la dramaturgia de la obra mientras que lo visto escenifica aquello escuchado.

Ejemplo: Jau (1986, Enrique Colina)

En segundo lugar, en las obras del periodo se reconoce una performatividad proactiva. En este caso, los personajes del mundo histórico reproducen exclusivamente para la cámara su acontecer. Así sucede en Wifredo Lam (1979, Humberto Solás), donde el pintor ejecuta su quehacer solo para ser "visto" por la cámara. La observación fílmica es núcleo activo con respecto a los eventos. De igual manera, sugiere una movilización de la realidad en función de su registro cinematográfico. ${ }^{45}$ Esta perspectiva es llevada al extremo en una obra como La espera (1983, Orlando Rojas). El filme reproduce las ensoñaciones de un hombre (el actor César Évora) que espera en un parque la llegada de su amada mientras es compelido permanentemente por los desechos y la suciedad que atesta el parque. Aquí se difumina la frontera entre el documental y la ficción, pues la trama está guiada a partir de una puesta en escena con actores y se experimenta un desplazamiento de la premisa, desde el móvil del personaje (drama de ficción, en este caso, la ansiedad por la llegada de su pareja), hacia las condiciones insalubres de la realidad cotidiana, proposición extraída del mundo histórico que adquiere progresivamente mayor relevancia a medida que avanza la historia.

En tercer lugar, en el documental cubano de los ochenta se distingue una performatividad evidencial. Aquí hay una diferenciación entre el plano visual y el plano sonoro. Este último es compuesto preferencial, no-diegético y movilizador del drama; mientras que, en el primero, representa las coyunturas descritas por el discurso hablado. En la etapa que se estudia, la obra que muestra con mayor desenfado este rasgo es Jau (1986), de Enrique Colina. Empleando una

45 Otros documentales que poseen estas características son: Crónica de una infamia (1982) y Hablas como si me conocieras (1989), de Irene López Kuchilán. 
voz en off, se exteriorizan las opiniones del personaje protagónico (el perro), lo cual guía la narración. Este filme emplea varios recursos formales, como el cambio del nivelado de la cámara y el uso de planos subjetivos para reforzar la idea de que el perro es el que interactúa con el espectador. Se emplea un montaje paralelo en el que las entrevistas intensifican la veracidad de la premisa de la película.

Hacia el final de la década se producen las primeras graduaciones de la Escuela Internacional de Cine y Televisión de San Antonio de los Baños (EICTV), lo cual dota al contexto cinematográfico cubano de nuevas perspectivas que anticipan el advenimiento de una nueva fase en los noventa. Al fin de los años ochenta, con su ideología popular y satírica, sobrevino en 1991 con la caída del campo socialista europeo y la entrada de Cuba en la profunda crisis económica y social conocida como el Período Especial.

La polémica desatada luego de la presentación pública de Alicia en el pueblo de maravillas (1991, Daniel Díaz Torres) demostró que el ambiente de distensión y diálogo entre instituciones, gobierno y audiencia que tipificó el mundo cultural de los ochenta había concluido. Expuso, de igual forma, la batalla simbólica en la que quedó inmerso el ICAIC ante el atrincheramiento político de la estructura gubernamental que dio un portazo de cierre a la crítica social como cualidad de la esfera pública en Cuba.

Sin embargo, algunos documentalistas extendieron su trabajo hasta los noventa, aunque en la mayoría de los casos con obras en las cuales se denota la mirada de la etapa que se cierra. Tal es el caso de El rey de la jungla (1990), de Enrique Colina y Hasta la reina Isabel baila el danzón (1991), de Luis Felipe Bernaza. También ocurre así con el Noticiero ICAIC, el cual, hasta su cierre en 1991, ofreció emisiones críticas sobre de la situación de diferentes asuntos que afectaban al país. Sobresale la figura de José Padrón, autor de la revista No.1 del Noticiero que lleva el título La Habana no aguanta más (1990), "que reflexiona sobre el problema de la vivienda en la capital, archivada sin haber logrado exhibirse ni una sola vez." 46 Padrón es el autor también de otros como Los albergados (1989), Un día de Atarés (1990).

\section{Conclusiones}

Este artículo se acercó al cine documental cubano producido por el ICAIC en los años ochenta. Propone que el entendimiento de una diacronía estética del mismo ha de ser ubicada entre los años 1979 y 1991. De igual manera, el texto pretende justipreciar un fenómeno obviado por la literatura de cine en Cuba y defiende que en este período se experimentó un despliegue de procedimientos comunicativos novedosos en el quehacer de la no-ficción realizada por el Instituto de Cine hasta entonces.

El presente texto abre al menos dos posibilidades de continuidad investigativa. La primera tiene que ver con que un elemento sobresaliente del periodo tratado es el surgimiento de focos de producción alternativos al ICAIC. Si bien se ubican más allá del horizonte del presente texto, este hecho es una novedad significativa merecedora de resaltar si se toma en consideración que el instituto funcionó hasta entonces como el monopolio absoluto de la creación fílmica en Cuba. Ann Marie Stock ha estudiado algunos de estos nuevos agentes que actuaron en el campo

46 Ochoa, op. cit. 
audio-visual de entonces, enfocándose, sobre todo, en una perspectiva institucional. ${ }^{47}$ Aunque ninguno de estos nuevos polos productivos tuvo una influencia comparada a la del ICAIC, es imprescindible mencionar que su gestión marcó el inicio de una mayor pluralización del ambiente cinematográfico cubano. El estudio de las cualidades estéticas de las producciones alternativas está aún pendiente, por lo que esta investigación aspira a funcionar como contrapeso para estudios comparativos futuros.

La segunda posibilidad está relacionada con la necesidad de incrementar los estudios formalistas sobre cine cubano. Ello permitiría una mejor comprensión de la evolución del uso de recursos estéticos y comunicativos en el documental producido por el ICAIC. El escaso empleo de la teoría cinematográfica en los estudios fílmicos en Cuba y la prominencia del marxismo como ideología ampliamente dominante en el entorno académico de la Isla, ha determinado una marcada preferencia por enfoques sociológicos. La aplicación de análisis enfocados en el texto audio-visual como un compendio de estrategias retóricas, debe asistir una a profundización del conocimiento del documental cubano.

El cine de la década del ochenta se desarrolló de forma muy dinámica, mostrando visiones más problematizadas de la realidad que en etapas precedentes. El estudio de los sub-géneros, realizado a partir del modelo provisto por Aufderheide, permitió demostrar tal hipótesis al comparar el aumento significativo de los documentales de 'asuntos públicos' y 'defensor', en detrimento del de 'propaganda gubernamental', clase ampliamente dominante en el decenio anterior. Es relevante resaltar, que esto no significa el destierro de dicho sub-género del documental ochentero, sino más bien una renegociación de las temáticas que posibilitó alcanzar un balance mucho más equilibrado entre varios de estos tipos. El documental (y también la ficción) asumió un rol de testigo, en algunas ocasiones, y de demandante, en otras, con respecto a cuestiones acuciantes de la vida social interna del acontecer nacional.

Ello determina que la crítica social se constituya como una de las claves imprescindibles de la no-ficción de los ochenta. El perfil activo en el señalamiento de conflictos fungió como baremo para el abordaje de nuevos asuntos, entre los que se destacan la burocracia y las incompetencias de los organismos estatales, cuestiones vinculadas a las relaciones de género y problemáticas tabú como la sexualidad en la adolescencia, el aborto y el embarazo precoz. Todas ofrecieron una apertura a la visión incorruptible de las aspiraciones de la sociedad socialista promovida durante los sesenta y, sobre todo, los setenta. La crítica social aportó una revitalización de un género que, para entonces, ya formaba parte de la tradición cinematográfica de la Isla.

El soporte retórico desarrollado por el documental para sostener sus puntos de vista fue la utilización del humor (clave 2) y de la sinergia entre ficción y no-ficción (clave 3); lo que favoreció una mayor comunicación con la audiencia sin perder la originalidad y la individualidad de cada realizador. Los géneros de la industria se complementaron unos con otros, cruzando fronteras, lo que propició una correlación muy interesante. La acción de varias generaciones de cineastas actuando en el mismo escenario dotó al documental de un impresionante alcance. Esta vez, el documental incorporó recursos provenientes de la ficción y expresados a través de distintas formas de performatividad. Las variaciones reactiva, proactiva y evidencial conforman un arsenal de recursos que determinó los modos de representación del mundo histórico. El

47 Stock, op. cit. 
rejuego de tal pléyade de mecanismos comunicativos demuestra la riqueza estética del documental cubano en los años ochenta.

\section{Bibliografía}

Aitken, Ian. The concise encyclopedia of the documentary film. New York: Routledge, 2013

Aufderheide, Patricia.Documentary film. A very short introduction. Oxford: Oxford University Press, 2007.

Beattie, Keith. Documentary screens: Non-fiction film and television. New York: Palgrave Macmillan., 2004

Bruzzi, Stella. New documentary. New York: Routledge, 2006.

Castillo, Luciano. "Rápida mirada al cine de los soñadores". En Luciano Castillo, et al, Conquistando la utopía. EL ICAIC y la Revolución 50 años después. La Habana: Ediciones ICAIC, 2010, pp. 11-41.

Chanan, Michael. Cuban cinema.Minnesota: University of Minnesota Press, 2004.

Del Río, Joel."La generación intermedia del cine cubano y la comedia popular”. En Edgar. Soberón (ed.) Los cines de América Latina y el Caribe. Parte 2. San Antonio de los Baños: Ediciones EICTV, 2013, pp. 146-148.

Del Río, Joel y Colina, Enrique. "Memories of Cuban Cinema, 1959-2015". En MaríaDelgado, Stephen Hart y Randall Johnson (eds.), A Companion to Latin American Cinema. Oxford: Wiley-Blackwell, 2017, pp. 219-237.

Díaz, Marta. y Del Río, Joel. Los cien caminos del cine cubano. La Habana: Ediciones ICAIC, 2010

Diéguez, Danae. "Cine de mujeres en Cuba". En Luciano Castillo, et al, Conquistando la utopía. EL ICAIC y la Revolución 50 años después. La Habana: Ediciones ICAIC, 2010, pp. 149-165.

Fanshel, Susan. A Decade of Cuban Documentary Film. New York: Young Filmmakers Foundation, 1982.

Fornet, Ambrosio.Las trampas del oficio. Apuntes sobre cine y sociedad. La Habana: Ediciones ICAIC, 2017, pp. 39-69.

García Borrero, Juan Antonio. “Vecinos”. En Paulo Antonio Paranaguá (ed.), Cine Documental en América Latina. Madrid: Ediciones Cátedra, 2003, pp. 387-388.

(2013). El perfecto neoanalfabeto y otras bloguerías. Santiago de Cuba: Editorial Oriente.

González Machado, Claudia. El Riesgo de la Herejía. Cartografía de la Crítica y el discurso Fílmico en la revista Cine Cubano (1960-2010). La Habana: Ediciones ICAIC, 2013.

Guevara, Alfredo. “Cine Cubano 1963". En Alfredo Guevara,Revolución es Lucidez. La Habana: Ediciones ICAIC, 1998, pp. 111-122.

Guevara, Alfredo. y Garcés, Raúl. Los años de la ira. Viña del Mar 67. La Habana: Ediciones Nuevo Cine Latinoamericano, 2007.

Lloga, Carlos Guillermo. "La hermenéutica ontológica como estrategia de interpretación de la realidad por el cine documental cubano de los años sesenta". Tesis para optar al grado de Máster en Estudios Cubanos y del Caribe. Santiago de Cuba: Universidad de Oriente, 2015.

(2019) "La construcción de la imagen local en los documentales producidos en el oriente de Cuba (1986-2016)." Tesis para optar al grado de Doctor en Film Studies and Visual Culture, Universidad de Amberes. 
Lloga, Carlos Guillermo y Silveira, David."Perspectivas de consenso y conflicto en el documental cubano de los sesenta. La hermenéutica ontológica como estrategia de interpretación de la realidad." Santiago 145, 2018, pp. 101-118.

Naito, Mario.“El documental cubano desde sus orígenes hasta nuestros días”. En Mario Naito (ed.), Coordenadas de cine cubano 2. Santiago de Cuba: Editorial Oriente, 2013, pp. 105-121. "El documental cubano en la década del setenta". En Armando Pérez (ed.), El cine, el crítico y el espectador que vino a cenar. Memorias del XVIII Taller Nacional de Crítica Cinematográfica. Santiago de Cuba, Editorial oriente, 2013, pp. 43-53.

Nichols, Bill. La Representación de la realidad. Cuestiones y conceptos sobre el documental.Barcelona: Paidós, 1997. Introduction to Documentary1st Ed. Bloomington: Indiana University Press, 2001. Introduction to Documentary2nd Ed. Bloomington y Indianapolis: Indiana University Press, 2010.

Ochoa, Marina. “Los años 80: ¿El gran espejismo?”En La pupila Insomne, 18 de agosto de 2007.Disponible en http://La Pupila Insomne: MARINA OCHOA SOBRE EL DOCUMENTAL DEL ICAIC EN LOS 80 _ cine cubano, la pupila insomne.htm(Consultado el 21 de abril de 2016).

Pérez Betancourt, Rolando. “Wifredo Lam”. Granma Resumen Semanal, 3 de octubre de 1982, p. 5. Producciones del Instituto Cubano de Arte e Industria Cinematográfica ICAIC 1959-2004. La Habana: Cinemateca de Cuba, 2004.

Sánchez, Jorge Luis.Romper la tensión del arco. Movimiento Cubano de Cine Documental.La Habana: Ediciones ICAIC, 2010.

Stock, Ann Marie.On location in Cuba. Street filmmaking during times of transition. North Carolina: The University of North Carolina Press, 2009.

Vega, Sara y Naito, Mario. Cartelera cinematográfica cubana (1960-2017). Santiago de Cuba: Editorial Oriente, 2018. 